\title{
Are frail elderly patients treated in a CGA unit more satisfied with their hospital care than those treated in conventional acute medical care?
}

This article was published in the following Dove Press journal:

Patient Preference and Adherence

\author{
Niklas Ekerstad ${ }^{1,2}$ \\ Göran Östberg ${ }^{3}$ \\ Maria Johansson ${ }^{3}$ \\ Björn W Karlson ${ }^{3,4}$ \\ 'Department of Cardiology, NU \\ (NÄL-Uddevalla) Hospital Group, \\ Trollhättan-Uddevalla-Vänersborg, \\ ${ }^{2}$ Department of Medical and Health \\ Sciences, Division of Health Care \\ Analysis, Linköping University, \\ Linköping, ${ }^{3}$ Division of Internal and \\ Acute Medicine, NU Hospital Group. \\ Trollhättan-Uddevalla-Vänersborg, \\ ${ }^{4}$ Department of Molecular and Clinical \\ Medicine, Institute of Medicine, \\ Sahlgrenska Academy, University of \\ Gothenburg, Gothenburg, Sweden
}

Correspondence: Niklas Ekerstad Department of Cardiology, NU (NAL-Uddevalla) Hospital Group, Lärketorpsvägen, 46100 Trollhättan, Sweden $\mathrm{Tel}+46736249652$ Fax +46 I04 $357 \quad$ I29 Email niklas.ekerstad@vgregion.se
Objectives: Our aim was to study whether the acute care of frail elderly patients directly admitted to a comprehensive geriatric assessment (CGA) unit is superior to the care in a conventional acute medical care unit in terms of patient satisfaction.

Design: TREEE (Is the TReatment of frail Elderly patients Effective in an Elderly care unit?) is a clinical, prospective, controlled, one-center intervention trial comparing acute treatment in CGA units and in conventional wards.

Setting: This study was conducted in the NÄL-Uddevalla county hospital in western Sweden. Participants: In this follow-up to the TREEE study, 229 frail patients, aged $\geq 75$ years, in need of acute in-hospital treatment, were eligible. Of these patients, 139 patients were included in the analysis, 72 allocated to the CGA unit group and 67 to the conventional care group. Mean age was 85 years and $65 \%$ were female.

Intervention: Direct admittance to an acute elderly care unit with structured, systematic interdisciplinary CGA-based care, compared to conventional acute medical care via the emergency room.

Measurements: The primary outcome was the satisfaction reported by the patients shortly after discharge from hospital. A four-item confidential questionnaire was used. Responses were given on a 4-graded scale.

Results: The response rate was $61 \%$. In unadjusted analyses, significantly more patients in the intervention group responded positively to the following three questions about the hospitalization: "Did you get the nursing from the ward staff that you needed?" ( $p=0.003)$, "Are you satisfied with the information you received on your diseases and medication?" ( $p=0.016)$, and "Are you satisfied with the planning before discharge from the hospital?" $(p=0.032)$. After adjusted analyses by multiple regression, a significant difference in favor of the intervention remained for the first question ( $p=0.027$ ).

Conclusion: Acute care in a CGA unit with direct admission was associated with higher levels of patient satisfaction compared with conventional acute care via the emergency room.

Keywords: frailty, elderly, comprehensive geriatric assessment, acute care, patient satisfaction, direct admission

\section{Introduction}

\section{Background}

Frailty is a biological syndrome reflecting vulnerability to stressors and reduced physiological reserves. ${ }^{1}$ It is associated with functional decline, activity limitations, prolonged recovery, and a high risk of being institutionalized and dying. ${ }^{2-5}$ Among older persons, the prevalence of frailty is estimated to be $10 \%-60 \%$, depending on the frailty 
assessment instrument used and the population studied. .,7 $^{6}$ Most of these patients have multiple chronic diseases and recurring episodes of acute illness.

Frail elderly individuals constitute a high percentage of emergency patients in every hospital. The current organization of acute care is often poorly adapted to the specific needs of these patients. To meet these needs, in 2008, the NU (NÄLUddevalla) hospital group in the Västra Götaland Region of Sweden introduced two acute elderly care comprehensive geriatric assessment (CGA) units (MÄVAs). ${ }^{8}$ The basic aims were to optimize the clinical treatment and thereby utilize health care resources in the best way. This form of care is characterized by direct admission and a structured, systematic multi- and interdisciplinary CGA and care performed in the ward, including an early rehabilitation strategy involving physicians, occupational therapists, physiotherapists, and nurses as active team members.

Previous clinical studies have indicated that frail elderly patients could benefit from a CGA. ${ }^{9-14}$

Patient satisfaction is an important patient-reported experience measure, and it can also be seen as an outcome in itself and as an integrated part of the results of every type of health care organization. It has been described as crucial for the evaluation of health care quality. ${ }^{15,16}$ In accordance with the consumer model, satisfaction can be regarded as a difference between expectations and assessed performance. ${ }^{17}$ On the other hand, it has been argued that it might be problematic to treat elderly patients as consumers. ${ }^{18}$ Patient satisfaction can also be defined as measuring the needs and wants, ${ }^{19}$ and it influences patient compliance as well as continuity of care. ${ }^{20,21}$

\section{Importance}

In acute care settings, there is, however, a lack of knowledge regarding the effects of CGA on health-related quality of life (HRQoL) and even more so on patient satisfaction. In the TREEE study (Is the TReatment of frail Elderly patients Effective in an Elderly care unit?), the results on HRQoL, activities of daily living (ADLs), mortality, and re-hospitalizations were favorable for the CGA units as described previously. ${ }^{14}$

In severely frail elderly patients with poor prognosis who need emergency care, the satisfaction with the received hospital care may be particularly important.

\section{Goals of the investigation}

Our aim in this follow-up of the TREEE study was to evaluate whether the acute care of frail elderly patients directly admitted to a CGA unit is superior to conventional acute medical care in terms of patient satisfaction. We hypothesized that a higher proportion of patients cared for in a CGA unit would report satisfaction compared with patients treated in a conventional care unit.

\section{Patients and methods Study design and setting}

This study on patient satisfaction used data from the TREEE study, a clinical, prospective, controlled intervention trial with two parallel groups performed at the NU hospital group between March 2013 and July 2015. Details of TREEE have been described earlier. ${ }^{14}$ The total primary population of the NU health care system is 280,000 inhabitants. The TREEE study was approved by the Independent Ethics Committee at the Sahlgrenska University Hospital in Gothenburg (8883-12, 20121212) and registered at the Swedish National Database of Research and Development (identifier: 113021). Written informed consent was obtained from the patients or from a member of their next of kin. All data were computerized and handled in accordance with legislation and Good Clinical Practice.

\section{Selection of participants}

TREEE included patients aged $\geq 75$ years, in need of inhospital treatment, and who fulfilled the foundation of frailty in accordance with the recently validated FRESH (FRail Elderly Support researcH group) screening instrument, ${ }^{22}$ that is, two or more of the following criteria: tiredness from a short walk, general fatigue, frequent falls/anticipation of falls, dependence in shopping, and three or more visits to the emergency ward during the last 12 months. Patients were excluded if they were clearly suited for care in a conventional acute medical care unit due to the type or severity of the acute illness.

When the ambulance nurse, or the primary care physician, had identified a patient who could fulfill the inclusion criteria, a MÄVA doctor was contacted via telephone. If he/she agreed, and there was a bed available at MÄVA, the patient was allocated to the intervention group and admitted directly to MÄVA. If bed was not available, the patient was allocated to the control group and admitted to a conventional acute medical care unit through the emergency room.

In the TREEE study, 408 patients were included between March 2013 and July 2015. For practical and resourcing reasons, we could not start the distribution of the questionnaire on patient satisfaction until February 2014. Between February 2014 and July 2015, 229 patients were 


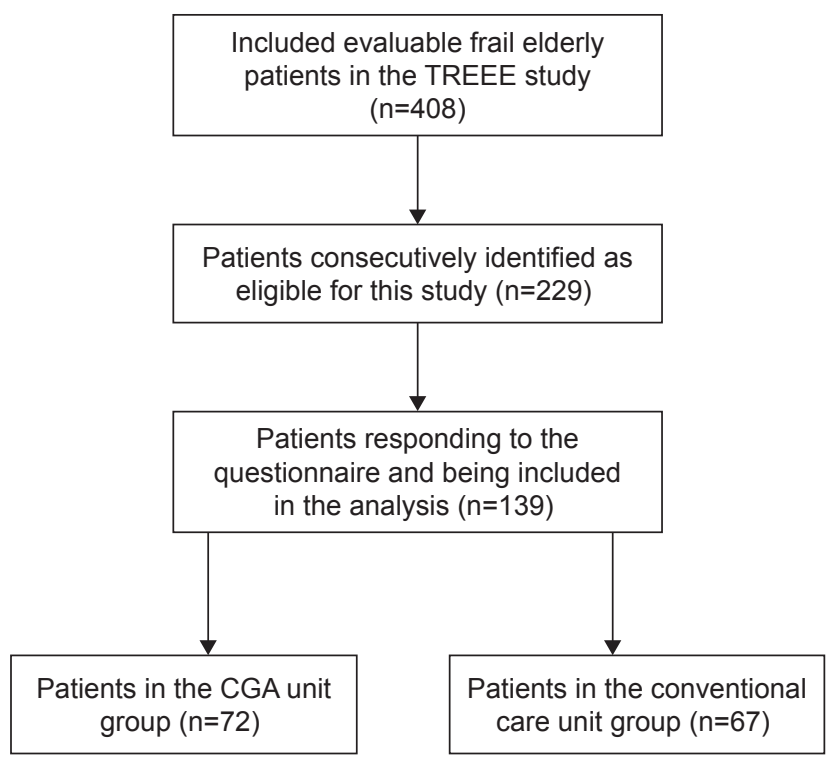

Figure I Flowchart of participant selection and assessment.

Abbreviations: TREEE, Is the TReatment of frail Elderly patients Effective in an Elderly care unit?; CGA, comprehensive geriatric assessment.

consecutively considered to be eligible in this part of the TREEE study (Figure 1).

\section{Intervention and control}

\section{Intervention group}

In addition to care in accordance with national and international guidelines, the CGA units are characterized by a structured, systematic interdisciplinary CGA and care via direct admittance to the wards (Table 1). The CGA involves physicians, nurses, occupational therapists, and physiotherapists as active team members. This implies a broad focus on physiological, psychological, and social factors via validated instruments, focusing on somatic and mental health, medication review, functional and activity ability including early rehabilitation, social situation, and early discharge planning. This also includes care guidance, adjusted to the needs of frail elderly patients. In order to individualize the assessment and treatment, the team has a person-centered approach. There are educational sessions in the intervention, including advice regarding physical exercise after discharge. There is a specially trained nurse responsible for the planning before discharge, with established contacts in primary care, home health care, and other types of support facilities.

A formal discussion with the patient and relatives and a total medicine treatment evaluation are included in the routine.

\section{Control group}

Patients are admitted to a conventional acute medical care unit via the emergency room, using standard clinical care and procedures in accordance with national and international guidelines. For both the groups, bedside medical examinations, electrocardiograms (ECGs), medical referrals, laboratory testing, X-ray examinations, blood transfusions, nutritional therapy, and drug treatment are included.

Table I Comparison of the management in the intervention group (CGA) and the control group (conventional acute medical care)

\begin{tabular}{|c|c|c|}
\hline & Comprehensive geriatric assessment and care & Conventional acute medical care \\
\hline Department and facilities & $\begin{array}{l}\text { Two MÄVA (acute elderly care CGA units) wards } \\
\text { with a total of } 48 \text { beds; one-, two-, or four-bed rooms } \\
\text { Division of Internal Medicine and Emergency Care }\end{array}$ & $\begin{array}{l}\text { Wards of internal and emergency medicine; one-, } \\
\text { two-, or four-bed rooms } \\
\text { Division of Internal Medicine and Emergency Care }\end{array}$ \\
\hline \multicolumn{3}{|l|}{ Team members } \\
\hline Physicians & $\begin{array}{l}\text { Yes. Specialists in internal medicine, family medicine } \\
\text { and/or geriatrics }\end{array}$ & Yes. Specialists in internal medicine \\
\hline Licensed practical nurses & $\begin{array}{l}\text { Yes. Including specialized admission and discharge } \\
\text { nurses }\end{array}$ & Yes \\
\hline Occupational therapists & Yes & No. Only counseling \\
\hline Physiotherapists & Yes & No. Only counseling \\
\hline Nutritionists & No. Only counseling & No. Only counseling \\
\hline Treatment & $\begin{array}{l}\text { Systematic, structured interdisciplinary comprehensive } \\
\text { geriatric assessment and care by validated instruments } \\
\text { focusing on somatic and mental health, medication } \\
\text { review, functional and activity ability including early } \\
\text { rehabilitation, social situation } \\
\text { Early discharge planning }\end{array}$ & $\begin{array}{l}\text { Following routines at departments of internal } \\
\text { medicine and emergency care in accordance with } \\
\text { guidelines }\end{array}$ \\
\hline Admission route & $\begin{array}{l}\text { Directly to the MÄVA ward via ambulance or primary } \\
\text { care }\end{array}$ & Via the emergency ward \\
\hline
\end{tabular}

Notes: Copyright @2017. Dove Medical Press. Reproduced from Ekerstad N, Karlson BW, Dahlin Ivanoff S, et al. Is the acute care of frail elderly patients in a comprehensive geriatric assessment unit superior to conventional acute medical care? Clin Interv Aging. 2017;12:1-9.14 For both the groups, standard management procedures in accordance with national and international guidelines were followed.

Abbreviation: CGA, comprehensive geriatric assessment. 


\section{Methods and measurements}

The data collection has previously been described in detail ${ }^{14}$ and is therefore only briefly repeated here.

\section{Clinical and demographic characteristics}

These data were collected at the index hospitalization: age, gender, housing, diabetes mellitus, renal function, heart failure, other comorbidities, mini nutritional assessment (MNA-short form), and numbers of in-hospital care days.

\section{The Charlson index score}

Charlson's comorbidity index (CCI) is a measurement of the total morbidity. ${ }^{23}$ It consists of 19 comorbidities, each of which is given a severity weighting depending on the risk of dying associated with this condition. The CCI was completed from medical records by the assessing physician.

\section{The FRESH screening instrument}

Frailty was assessed using the FRESH screening instrument, ${ }^{22}$ which is a validated screening instrument for frailty shown to be appropriate in an emergency hospital setting. It consists of five questions (see the "Selection participants" section). The FRESH screening instrument was performed by a physician or a nurse at the time of inclusion.

\section{ADL}

ADL independence/dependence was assessed by using the ADL Staircase before discharge. ${ }^{24}$ This instrument consists of five personal ADL (PADL) items (ie, feeding, transferring, going to the toilet, dressing, and bathing), extended by four instrumental ADL (IADL) items (ie, cooking, shopping, cleaning, and transportation). The ADL Staircase was administered through interview and, if possible, observation.

\section{The satisfaction questionnaire}

From February 2014 to July 2015, the patients were provided with a confidential satisfaction questionnaire to be filled in shortly after discharge from hospital by the patient alone, or with the help of relatives. The patient satisfaction questions were based on the experience with physicians and other team members in the MÄVA units and on questions and topics often brought up by patients and relatives. The aim was to create simple, clinically relevant questions, easy to respond to by ticking one of four options. The questions were carefully discussed internally, and we consulted broadly with geriatric expertise. Questions of the same kind have been used before, ${ }^{25-27}$ but not previously been formally validated in an acute care context.
The questionnaire included four questions regarding patient satisfaction during the hospitalization period:

1. Did you get help from the doctors with the medical problems you came in for? (1)

2. Did you get the nursing from the ward staff that you needed? (2)

3. Are you satisfied with the information you received on your diseases and medication? (3)

4. Are you satisfied with the planning before discharge from the hospital? (4)

The alternatives for answers to the questions were:

(1) Great help, fairly great help, little help and very little help; (2) Yes always, yes often, no not often, and no seldom; (3) and (4) Very satisfied, fairly satisfied, fairly unsatisfied, and very unsatisfied.

\section{Outcomes}

The primary outcome was the level of satisfaction on each question reported by the patient after the index hospitalization.

\section{Analysis}

For the TREEE study, it was estimated that 200 evaluable patients should be included in each study group. ${ }^{14}$ The two first response alternatives to each of the four questions were considered as positive, the remaining two responses to each question were considered as negative, that is, for each question, the responses were dichotomized before analysis. The data were computerized and analyzed using the Statistical Package for the Social Sciences (IBM SPSS Statistics for Windows, Version 22.0; IBM Corporation, Armonk, $\mathrm{NY}$, USA). Student's $t$-test was used to compare the continuous, parametric data between the groups, and the $\chi^{2}$ test or Fisher's exact test was used to compare the categorical data. Adjustments for possible differences at baseline were made, using a logistic regression model including age, gender, and CCI score as covariates.

\section{Results}

\section{Characteristics of study subjects}

In this follow-up to the TREEE study, 229 frail patients were consecutively identified to be eligible. Of these patients, 139 patients being allocated to the CGA unit group $(n=72)$ or conventional ward group ( $\mathrm{n}=67$ ) responded to the questionnaire and were included in the analysis. The response rate was $61 \%$.

Baseline clinical and demographic characteristics are presented in Table 2. The two groups did not differ 
Table 2 Baseline clinical and demographic characteristics of the intervention and control group patients who responded to the satisfaction questionnaire

\begin{tabular}{|c|c|c|c|}
\hline Characteristics & $\begin{array}{l}\text { Intervention } \\
\text { group } \\
(\mathrm{n}=72)\end{array}$ & $\begin{array}{l}\text { Control } \\
\text { group } \\
(n=67)\end{array}$ & $p$-value \\
\hline Age, mean (years) (SD) & $85.6(5.5)$ & $85.1(5.6)$ & 0.538 \\
\hline Gender, male, n (\%) & $24(33.3)$ & $23(34.3)$ & 1.000 \\
\hline Charlson score, ${ }^{*}$ mean $(S D)$ & $7.2(2.1)$ & $6.0(1.2)$ & $<0.001$ \\
\hline ADL score, ${ }^{* *}$ mean $(S D)$ & $\begin{array}{l}4.5(2.6) \\
(n=7 I)\end{array}$ & $\begin{array}{l}3.9(2.6) \\
(n=66)\end{array}$ & 0.185 \\
\hline Frailty score, ${ }^{\S}$ mean $(\mathrm{SD})$ & $3.4(0.85)$ & $3.1(0.91)$ & 0.046 \\
\hline MNA score," mean (SD) & II.3 (2.4) & $\begin{array}{l}10.5(2.5) \\
(n=66)\end{array}$ & 0.065 \\
\hline Residential care, $\mathrm{n}(\%)$ & $8(I I . I)$ & $8(11.9)$ & 1.000 \\
\hline Hypertension, n (\%) & $60(83.3)$ & $49(73.1)$ & 0.155 \\
\hline Ischemic heart disease, $\mathrm{n}(\%)$ & $20(27.8)$ & $18(26.9)$ & 1.000 \\
\hline Chronic heart failure, $\mathrm{n}(\%)$ & $38(52.8)$ & $20(29.9)$ & 0.010 \\
\hline Cerebrovascular disease, $\mathrm{n}(\%)$ & $22(30.6)$ & $16(23.9)$ & 0.448 \\
\hline COPD, n (\%) & $7(9.7)$ & $46(68.7)$ & 0.003 \\
\hline Tumor, n (\%) & $9(12.5)$ & $4(6.0)$ & 0.248 \\
\hline Dementia, n (\%) & $4(5.6)$ & $7(10.5)$ & 0.354 \\
\hline Anemia, n (\%) & $39(54.2)$ & $35(52.2)$ & 0.866 \\
\hline Diabetes, n (\%) & $12(16.7)$ & $13(19.4)$ & 0.826 \\
\hline LOS index, days, mean, $\mathrm{n}(\mathrm{SD})$ & II .8 (5.9) & $7.7(6.4)$ & $<0.001$ \\
\hline
\end{tabular}

Notes: $* \mathrm{CCl}$ score is a measurement of the total morbidity. **ADL independence/ dependence was assessed by using the ADL Staircase before discharge. ${ }^{\circledR}$ Frailty was assessed using the FRESH screening instrument. "MNA-short form was used to describe nutritional status. Please see also methods section.

Abbreviations: FRESH, FRail Elderly Support researcH group; $\mathrm{CCl}$, Charlson's comorbidity index; ADL, activities of daily living; MNA, mini nutritional assessment: LOS, length of stay.

significantly in terms of age, gender, scores of ADL and MNA, and percentage living in residential care (all $p>0.05$ ). The intervention group presented with higher scores of frailty ( $p=0.046)$ and Charlson comorbidity index $(p<0.001)$. Both the groups were heavily affected by diseases, particularly cardiovascular disease. Furthermore, dependence or difficulty carrying out PADL or IADL were common among the participants in both the groups.

\section{Main results}

The responses to the four questions of the satisfaction questionnaire are reported in Table 3. For each question, the proportions of chosen alternatives on the 4-graded scale are referenced. In the intervention group, the responses were given by the patient alone in 36 cases, a next-of-kin in 11 cases, and a combination in 25 cases. In the control group, the responses were given by the patient alone in 28 cases, a next-of-kin in 11 cases, and a combination in 28 cases.

Unadjusted analysis of the dichotomized responses of the questionnaire is shown in Table 4. Significantly more patients in the intervention group responded positively to the following three questions: "Did you get the nursing from the ward staff that you needed?" ( $p=0.003)$, "Are you satisfied with the information you received on your diseases and medication?" ( $p=0.016)$, and "Are you satisfied with the planning before discharge from the hospital?" ( $p=0.032)$. There was no difference between the groups in response to the question "Did you get help from the doctors with the medical problems you came in for?" $(p=0.120)$.

After adjusting for age, gender, and Charlson's index in multiple regression analyzes, a statistically significant difference in favor of the intervention remained for the second question "Did you get the nursing from the ward staff that you needed?" ( $p=0.027)$. Neither regarding the question "Are you satisfied with the information you received on your diseases and medication?" $(p=0.059)$, nor for the responses of the other two questions (both $p>0.05$ ), there were any statistically significant differences in favor of the

Table 3 The responses of patients in each group to the four questions of the satisfaction questionnaire, $\mathrm{n}(\%)$

\begin{tabular}{|c|c|c|c|c|}
\hline $\begin{array}{l}\text { Did you get help from the doctors with } \\
\text { the medical problems you came in for? }\end{array}$ & Great help & Fairly great help & Little help & Very little help \\
\hline Intervention group $(\mathrm{n}=72)$ & $33(45.8)$ & $29(40.3)$ & $4(5.6)$ & $6(8.3)$ \\
\hline Control group $(n=66)$ & $26(39.4)$ & $24(36.4)$ & 14 (2I.2) & $2(3.0)$ \\
\hline $\begin{array}{l}\text { Did you get the nursing from the ward } \\
\text { staff that you needed? }\end{array}$ & Yes, always & Yes, often & No, not often & No, seldom \\
\hline Intervention group $(\mathrm{n}=67)$ & $43(64.2)$ & $23(34.3)$ & $0(0)$ & I (I.5) \\
\hline Control group $(n=66)$ & $38(57.6)$ & $17(25.7)$ & $6(9.1)$ & $5(7.6)$ \\
\hline $\begin{array}{l}\text { Are you satisfied with the information you } \\
\text { received on your diseases and medication? }\end{array}$ & Very satisfied & Fairly satisfied & Fairly unsatisfied & Very unsatisfied \\
\hline Intervention group $(\mathrm{n}=7 \mathrm{I})$ & $28(39.4)$ & $36(50.7)$ & $4(5.6)$ & $3(4.3)$ \\
\hline Control group $(n=67)$ & $23(34.3)$ & $27(40.3)$ & $10(15.0)$ & $7(10.4)$ \\
\hline $\begin{array}{l}\text { Are you satisfied with the planning before } \\
\text { discharge from the hospital? }\end{array}$ & Very satisfied & Fairly satisfied & Fairly unsatisfied & Very unsatisfied \\
\hline Intervention group $(\mathrm{n}=72)$ & $38(52.8)$ & $26(36.0)$ & $4(5.6)$ & $4(5.6)$ \\
\hline Control group $(n=65)$ & $24(36.9)$ & $24(36.9)$ & I3 (20.0) & $4(6.1)$ \\
\hline
\end{tabular}


Table 4 Unadjusted analysis of the dichotomized responses

\begin{tabular}{|c|c|c|c|}
\hline & $\begin{array}{l}\text { Intervention } \\
\text { group } \mathbf{n}(\%)\end{array}$ & $\begin{array}{l}\text { Control } \\
\text { group n (\%) }\end{array}$ & $p$-value \\
\hline \multicolumn{3}{|c|}{$\begin{array}{l}\text { Did you get help from the doctors with the medical problems } \\
\text { you came in for? }\end{array}$} & 0.120 \\
\hline Great help, fairly great help & $62(86.1)$ & $50(75.8)$ & \\
\hline Little help, very little help & $10(13.9)$ & $16(24.2)$ & \\
\hline \multicolumn{3}{|c|}{ Did you get the nursing from the ward staff that you needed? } & 0.003 \\
\hline Yes always, yes often & $66(98.5)$ & $55(83.3)$ & \\
\hline No not often, no seldom & $\mathrm{I}(\mathrm{I} .5)$ & II (I6.7) & \\
\hline \multicolumn{3}{|c|}{$\begin{array}{l}\text { Are you satisfied with the information you received on your } \\
\text { diseases and medication? }\end{array}$} & 0.016 \\
\hline Very satisfied, fairly satisfied & $64(90.1)$ & $50(74.6)$ & \\
\hline $\begin{array}{l}\text { Fairly unsatisfied, } \\
\text { very unsatisfied }\end{array}$ & $7(9.1)$ & $17(25.4)$ & \\
\hline \multicolumn{3}{|c|}{$\begin{array}{l}\text { Are you satisfied with the planning before discharge from the } \\
\text { hospital? }\end{array}$} & 0.023 \\
\hline Very satisfied, fairly satisfied & $64(89.0)$ & $48(74.0)$ & \\
\hline $\begin{array}{l}\text { Fairly unsatisfied, } \\
\text { very unsatisfied }\end{array}$ & $8(11.0)$ & $17(26.0)$ & \\
\hline
\end{tabular}

Note: The two first response alternatives to each question were considered as positive, the remaining two responses were considered as negative, that is, for each question, the responses were dichotomized before analysis.

intervention group. For the questions "Are you satisfied with the information you received on your diseases and medication?" and "Are you satisfied with the planning before discharge from the hospital?" there was a correlation between satisfaction and higher age (both $p<0.05$ ).

\section{Discussion}

Our study shows that acute care of elderly, frail patients directly admitted to a CGA unit was associated with significantly higher levels of patient satisfaction compared with conventional acute care for three of the four components registered.

This difference in favor of the intervention remained partly also after adjusting for age, gender, and comorbidity with a statistically significant difference for the question "Did you get the nursing from the ward staff that you needed?"

In both the study groups, a broad majority of the patients reported overall positive satisfaction scores. Furthermore, for two of the questions, there was an association between positive answers and high age. This harmonizes with previous studies, indicating an association between patient satisfaction and age, ${ }^{28,29}$ particularly among female elderly patients. ${ }^{19}$ In the current study, the mean age was 85 years, and the majority were females.

There is a growing evidence in favor of CGA units for frail elderly patients. The CGA and related care can be considered a complex intervention. Consequently, there may be several critical differences compared to conventional care, which may interact and benefit frail elderly patients with accompanying higher patient satisfaction.
The previously reported results of the broader study indicates that well-structured team-based acute care for frail elderly patients in a CGA unit is superior to the care in a conventional acute medical care unit in terms of several clinically meaningful outcomes. The satisfaction results might be linked to these positive outcomes from the TREEE study. ${ }^{14}$

Moreover, in recent studies, it has been emphasized that patient involvement, participation, and communicating with patients about motivations and expectations might lead to higher satisfaction. ${ }^{19,30,31} \mathrm{~A}$ person-centered approach in order to individualize the assessment and treatment, which was applied by the team in the intervention group, might have facilitated these values.

Furthermore, patients in the intervention group were directly admitted to the CGA care unit. In a previous study in an emergency context, long waiting times at the reception were associated with dissatisfaction. ${ }^{32-34}$ It can also be hypothesized that longer hospital stay in the intervention group made it possible to optimize the medical treatment, to inform the patients and relatives in more detail and to perform a more extensive care planning in cooperation with other care-givers. This might be another part of the explanation for the higher satisfaction in the CGA group.

Elderly patients are so severely affected by frailty and multi-morbidity as our study patients generate a large part of everyday hospital care consumption in most western countries. There is therefore a particular need to build evidence relating to the treatment and care of this important patient group. Patient satisfaction is an integrated and important part of that work. This study was integrated in the standard daily clinical context and included a wide spectrum of diagnoses, which enhances the generalizability of the study results. Moreover, we studied very frail elderly patients in need of acute care, which adds complementary knowledge to former studies focusing on patients in a more stable and chronic phase.

The MÄVA form of care can serve as one example of how acute care for frail elderly people can be organized. More research is needed to identify the most appropriate organizational forms adapted to the varying needs of the frail elderly patients, for example, stable chronic disease and acute illness. This further research should include evaluations of primary and municipal care, ambulant geriatric care, and specialized hospital care. In every such study, the evaluation of patient satisfaction should be an important part.

\section{Limitations}

Our patient satisfaction study has some limitations, the main one being that the questions used in this survey are not 
formally validated. However, we wanted to take the opportunity to capture the opinions of our patients on these few, short, and clinically relevant questions. In addition, we did not find any validated instrument that fulfilled the needs of the TREEE study. The questions were based on available literature and intense discussions and broad consultations with experts. Another limitation is the low number of patients. However, the response rate of $61 \%$ is in the range of what has previously been reported in this kind of population.

\section{Conclusion}

Acute care in a CGA unit with direct admission was associated with higher levels of patient satisfaction compared with conventional acute care via the emergency room.

\section{Acknowledgments}

This study was funded by grants from the Healthcare subcommittee, Region Västra Götaland; Department of Research and Development, NU Hospital Group; and the Fyrbodal Research and Development Council, Region Västra Götaland, Sweden.

\section{Disclosure}

The authors report no conflicts of interest in this work.

\section{References}

1. Bergman H, Ferrucci L, Guralnik J, et al. Frailty: an emerging research and clinical paradigm. Issues and controversies. J Gerontol A Biol Sci Med Sci. 2007;62:731-737.

2. Fried LP, Tangen CM, Walston J, et al. Frailty in older adults: evidence for a phenotype. J Gerontol A Biol Sci Med Sci. 2001;56:146-156.

3. Rockwood K, Song X, MacKnight C, et al. A global clinical measure of fitness and frailty in elderly people. Can Med Assoc J. 2005;173: 489-495.

4. Shamliyan T, Talley KMC, Ramakrishnan R, Kane RL. Association of frailty with survival: a systematic literature review. Ageing Res Rev. 2012;12:719-736.

5. Buta BJ, Walston JD, Godino JG, et al. Frailty assessment instruments: Systematic characterization of the uses and contexts of highly-cited instruments. Ageing Res Rev. 2016;26:53-61.

6. Afilalo J, Karunananthan S, Eisenberg MJ, Alexander KP, Bergman H. Role of frailty in patients with cardiovascular disease. Am J Cardiol. 2009;103:1616-1621.

7. Collard RM, Boter H, Schoevers RA, Oude Voshaar RC. Prevalence of frailty in community-dwelling older persons: a systematic review. J Am Geriatr Soc. 2012;60:1487-1492.

8. Johansson M, Johansson P. Multisjuka äldre med upprepade vårdtillfällen bör läggas in direkt. Läkartidningen. 2012;109:1022-1023. Swedish.

9. Ekdahl AW, Wirehn AB, Alwin J, et al. Costs and effects of an ambulatory geriatric unit (the AGe-FIT study): a randomized controlled trial. J Am Med Dir Assoc. 2015;16(6):497-503.

10. Prestmo A, Hagen G, Sletvold O, et al. Comprehensive geriatric care for patients with hip fractures: a prospective, randomised, controlled trial. Lancet. 2015;385:1623-1633.

11. Ellis G, Gardner M, Tsiachristas A, et al. Comprehensive geriatric assessment for older adults admitted to hospital. Cochrane Database Syst Rev. 2011;7:CD006211.
12. SBU. Comprehensive geriatric assessment and care of frail elderly. Stockholm: Swedish Council on Health Technology Assessment (SBU); 2014. SBU report no 221 (in Swedish). Available from: http://www. sbu.se/upload/Publikationer/Content0/1/Akutvard_aldre.pdf; Accessed May 7, 2016.

13. Baztán JJ, Suárez-García FM, López-Arrieta J, Rodríguez-Mañas L, Rodríguez-Artalejo F. Effectiveness of geriatric units on functional decline, living at home, and case fatality among older patients admitted to hospital for acute medical disorders: meta-analysis. BMJ. 2009; 338:b50.

14. Ekerstad N, Karlson BW, Dahlin Ivanoff S, et al. Is the acute care of frail elderly patients in a comprehensive geriatric assessment unit superior to conventional acute medical care? Clin Interv Aging. 2017;12: $1-9$.

15. Danielsen K, Bjertnaes O, Garratt A, Forland O, Iversen HH, Hunskaar S The association between demographic factors, user reported experiences and user satisfaction: results from three casualty clinics in Norway. BMC Fam Pract. 2010;11:73.

16. Prakash B. Patient satisfaction. J Cutan Aesthet Surg. 2010;3(3): 151-155.

17. Clausen G, Borchelt M, Janssen C, et al. Patient satisfaction and geriatric care - an empirical study. Z Gerontol Geriatr. 2006;39:48-56.

18. Owens DJ, Batchelor C. Patient satisfaction and the elderly. Soc Sci Med. 1996;42(11):1483-1491.

19. Chumbler NR, Otani K, Desai SP, Herrmann PA, Kurz RS. Hospitalized older adults' patient satisfaction. SAGE Open. 2016;6:1-7.

20. Linn LS. Factors associated with patient satisfaction of healthcare. Milbank Mem Fund Q Health Soc. 1975;53:531-548.

21. Xiao H, Barber JP. The effect of perceived health status on patient satisfaction. Value Health. 2008;11:719-725.

22. Eklund K, Wilhelmson K, Landahl S, Ivanoff-Dahlin S, Synneve ID. Screening for frailty among older emergency department visitors: validation of the new FRESH-screening instrument. BMC Emerg Med. 2016;16:27.

23. Charlson M, Pompei P, Ales KL, MacKenzie CR. A new method of classifying prognostic comorbidity in longitudinal studies: development and validation. J Chronic Dis. 1987;40:373-383.

24. Sonn U, Hulter-Åsberg K. Assessment of activities of daily living in the elderly. Scand J Rehabil Med. 1991;23:193-202.

25. Arnetz JE, Arnetz B. The development and application of a patient satisfaction measurement system for hospital-wide quality improvement. Int J Qual Health Care. 1996;8:555-566.

26. Broadbent E, Petrie KJ, Main J, Weinman J. The brief illness perception questionnaire. J Psychosom Res. 2006;60:631-637.

27. Berglund $\mathrm{H}$, Wilhelmson K, Blomberg S, Dunér A, Kjellgren K, Hasson H. Older people's views of quality of care: a randomized controlled study of continuum of care. J Clin Nurs. 2013;22:2934-2944.

28. Bene J, Liston R, Nelson L, et al. Elderly patients' satisfaction with hospital care. J R Coll Physicians Lond. 1998;32(2):138-141.

29. Peck B. Age-related differences in doctor-patient interaction and patient satisfaction. Curr Gerontol Geriatr Res. 2011;2011:13749.

30. Li W, Wang S, Zhang Y. Relationships among satisfaction, treatment motivation, and expectations in orthodontic patients: a prospective cohort study. Patient Prefer Adherence. 2016;10:443-447.

31. Keita I, Aubin-Auger I, Lalanne C, et al. Assessment of quality of life, satisfaction with anticoagulation therapy, and adherence to treatment in patients receiving long-course vitamin $\mathrm{K}$ antagonists or direct oral anticoagulants for venous thromboembolism. Patient Prefer Adherence. 2017;11:1625-1634

32. Taylor C, Benger JR. Patient satisfaction in emergency medicine. Emerg Med J. 2004;21:528-532.

33. Hedges JR, Trout A, Magnusson AR. Satisfied patients exiting the emergency department (SPEED) study. Acad Emerg Med. 2002;9: $15-21$.

34. Rahmqvist M, Bara AC. Patient characteristics and quality dimensions related to patient satisfaction. Int J Qual Health Care. 2010; 22:86-92. 


\section{Publish your work in this journal}

Patient Preference and Adherence is an international, peer-reviewed, open access journal that focuses on the growing importance of patient preference and adherence throughout the therapeutic continuum. Patient satisfaction, acceptability, quality of life, compliance, persistence and their role in developing new therapeutic modalities and compounds to optimize

clinical outcomes for existing disease states are major areas of interest for the journal. This journal has been accepted for indexing on PubMed Central. The manuscript management system is completely online and includes a very quick and fair peer-review system, which is all easy to use. Visit http://www. dovepress.com/testimonials.php to read real quotes from published authors.

Submit your manuscript here: http://www.dovepress.com/patient-preference-and-adherence-journal 